\title{
Active control for mid-span connection of a deployable tensegrity footbridge
}

\author{
Nicolas Veuve', Seif Dalil Safaei ${ }^{2}$, Ian F.C. Smith ${ }^{3}$
}

\begin{abstract}
Tensegrity structures are spatial self-stressed pin-jointed structures where compression components (struts) are surrounded by tension elements. This paper describes a near full-scale deployable tensegrity footbridge that deploys from both sides and connects at mid-span. Two topologies that differ in terms of symmetry of elements and paths of continuous cables are compared. Although both topologies behave similarly with respect to serviceability criteria, there is a significant difference in behavior during deployment. A two-stage control methodology for the connection of both halves of the footbridge is presented. The control methodology determines active cable length changes based on computational control and measurement of the response of the structure during deployment. Both halves are successfully connected at the end of deployment.
\end{abstract}

Keyword: Tensegrity, footbridge, topology, computational control, active structures

${ }^{1} \mathrm{Ph} . \mathrm{D}$. Student, Applied Computing and Mechanics Laboratory, School of Architecture, Civil and Environmental Engineering (ENAC), Swiss Federal Institute of Technology (EPFL), Lausanne, Switzerland (corresponding author). E-mail: nicolas.veuve@epfl.ch

${ }^{2}$ Postdoctoral Researcher, Applied Computing and Mechanics Laboratory, School of Architecture, Civil and Environmental Engineering (ENAC), Swiss Federal Institute of Technology (EPFL), Lausanne, Switzerland.

${ }^{3}$ Professor, Applied Computing and Mechanics Laboratory, School of Architecture, Civil and Environmental Engineering (ENAC), Swiss Federal Institute of Technology (EPFL), Lausanne, Switzerland. 


\section{Introduction}

Motro [1] defined tensegrity structures as self-stressed and pin-jointed assemblies of compression elements inside a network of tension elements. Skelton [2] classified tensegrity structure as "class k" with " $k$ " being the number of struts that are linked together at the nodes. Tensegrity structures are good candidates for deployment because structural elements can be used as active elements. In addition, Caluwaerts et. al. [3] showed that the stress distribution can be modified in redundant tensegrity structures without altering the equilibrium shape and conserving a constant energy level. Therefore tensegrity structures are good candidates for energy-efficient adaptive structures.

Shape control has been demonstrated using tensegrity structures and other pin-jointed structures such as trusses and Geiger domes. Ziegler [4] presented analytical and simulation results of a method for shape control of discrete structures such as a truss that does not result in additional stress. Domer et. al. [5] controlled the deflections of a tensegrity grid under several load cases. The control commands were obtained from stochastic search methods combined with structural analysis. Adam and Smith [6] evaluated the ability of a tensegrity grid to improve the performance of adaptation to new load cases through reinforcement learning. Dalil Safaei et. al. [7] showed that the bending stiffness of a tensegrity boom was improved with appropriate actuator placement and computed the actuation with genetic algorithms combined with a nonlinear finite element method. Shon et. al. [8] numerically studied the shape adjustment of a Geiger dome. Kmet et al. [9] studied and tested a tensegrity module which was able to adapt its geometrical form and pre-stress properties to external conditions. Experimental results verified close-form predictions. Although these studies demonstrate efficient control strategies in terms of shape and stress adaptation, shape changes are small compared with what is needed for deployment.

It is often assumed that structural control is useful only for mitigating vibration. Ganesh Raja and Narayanan [10] analytically studied the control of random vibrations in a two stage, three-strut tensegrity structure. Bel Hadj Ali and Smith [11] showed the feasibility of modifying the selfstress level in order to shift the natural frequencies away from the excitation frequency range. The self-stress was modified through changes in strut length computed from a combination of stochastic search and structural analyses. El Ouni and Ben Kahla [12] optimized the number of sensors and actuators in a Geiger dome and proposed active tendon control for vibration 
attenuation. Amouri et. al. [13] proposed a methodology for the attenuation of the first vibration mode of a tensegrity grid. They demonstrated on a full-scale tensegrity grid that their methodology performs efficiently for flexural modes even in the presence of random force excitation. These studies showed that dynamic behavior can be improved by activating the elements in tensegrity structures. None of these studies involved deployment.

Tensegrity structures have been used in robotics. Graells Rovira and Mirats Tur [14] established through simulations that a tensegrity-based mobile robot is able to follow a desired path on flat surfaces. Caluwaerts et al. [15] studied control methods for the locomotion of a compliant spherical tensegrity robot on complex terrains. They showed that simulations of the locomotion of the spherical tensegrity were in good agreement with prototype measurements. Bliss et. al. [16] demonstrated the robustness of a central pattern generator control for the motion of a tensegrity swimmer where cables were used to be simultaneously actuators and sensors. Although there are several successes in the field of robotic tensegrity structures, civil tensegrity structures differ in size and design goals since there are, for example, restrictive needs related to serviceability criteria.

Those who have studied tensegrity structure deployment focused on simple configurations. Pinaud et al. [17] studied the deployment of a small-scale class 2 tensegrity tower. Schenk et. al. [18] used springs in order to design and test a statically balanced deployable tensegrity structure. The deployment of a near-full scale class 1 tensegrity reflector was analysed and tested by Zolesi et al. [19]. Tests of this structure showed deployment repeatability. Zhang et. al. [20] described the cable-controlled reconfigurations of tensegrity structures based on a symmetrical state of selfstress maintaining a constant strain energy level. Xu et. al. [21] proposed a path planning method avoiding internal strut contact and obstacle collision for the shape change of active tensegrity structures. Sultan [22] studied a three stage tensegrity tower and showed that deployment along infinitesimal-mechanism direction does not dissipate energy. Possible non-repeatable deployment was not addressed.

Most studies on locomotion and deployment are related to tensegrities where no joint modelling is required either because they are built at a small scale, or joint-related modelling challenges are small because they belong to class-1 tensegrity structures. A recent study by the authors [23] on tensegrity deployment demonstrated that joint eccentricities and friction in a near full-scale 
tensegrity structure of class 2 and higher lead to non-repeatable deployment behavior. In addition simulations performed with frictionless and dimensionless joints result are not accurate. Active control is employed in this paper to accommodate these aspects.

Pugh [24] first described tensegrity ring modules. Motro et. al. [25] showed that a tensegrity ring module is deployable. Cevaer et. al. [26] studied the compression mechanical behaviour of a deployable tensegrity ring. Rhodes-Barbarigos et. al. [27] studied the mechanism-based approach for the deployment and the design aspects [28] of a deployable tensegrity footbridge composed of four tensegrity ring modules. Challenges related to the mid-span connection of the footbridge have not yet been examined.

This paper proposes a control methodology for the connection of both halves of a near full-scale deployable tensegrity footbridge. More specifically, objectives are to compare two configurations of the footbridge in terms of serviceability performance and deployed shape prior to mid-span connection. Control commands that are computed from a combination of stochastic search and quasi-static analyses of the structure assuming frictionless and dimensionless joints are then tested. Finally, an additional control command search based on measurement of the real structural response to active cable length changes during deployment is verified experimentally.

\section{Deployable tensegrity footbridge}

The structure is a $1 / 4$-scale model of a deployable tensegrity footbridge (see Figure 1). Rules of similitude and modelling have been respected so that strains on the $1 / 4$ scale model are the same as would be experienced by a full-scale structure. The structure is composed of steel struts that are hollow tubes with a $28[\mathrm{~mm}]$ diameter and $1.5[\mathrm{~mm}]$ thickness, steel cables with a cross section

of $11\left[\mathrm{~mm}^{2}\right]$, and spring elements made of steel with a stiffness of $2[\mathrm{kN} / \mathrm{m}]$ at the support and 2.9 $[\mathrm{kN} / \mathrm{m}]$ at other locations. The structure contains two types of cables, non-continuous and continuous cables. Non continuous cables are cables composed of one segment and they end at the joints that define the segment.

A continuous cable is a cable that has at least one intermediate joint between its two end joints. Intermediate joints allow cable sliding (relative displacement between the cable and its intermediate nodes). Equilibrium equations of tensegrity structures with continuous cables were first derived by Moored and Bart-Smith [29] who called them clustered cables. 
All continuous cables in the deployable tensegrity structure are actuated. The continuous cable ends located at the support are rolled and attached to drums. Continuous cable length is changed through winding or unwinding the cable on the drum. The actuators are DC motors. They rotate the drums where cables are winded with a reduction gear (1:256) and are used with a position control mode. The end nodes (where continuous cables are actuated) are placed on rail-supports. The orientation of the rail supports are indicated on Figure 2 and the supports are blocked in the three directions when the two bridge halves are connected and pre-stressed.

Spring elements have a maximal length when the structure is folded. Deployment is controlled through increasing length of continuous cables and springs contribute since they progressively release their elastic deformation energy during deployment. The combination of continuous cables and springs is an actuation scheme that reduces the number of actuators required for deployment and has the advantage of actuators located only at the supports [27]. Current deployment takes approximately five minutes to be performed. Deployment speed was kept very low to avoid possible dynamic effects. No dynamic effects were observed and therefore, it is likely that a faster speed is possible.

Excessive bending in struts when the structure is folded leads to a reduction of cable stresses from the design cable stress. Strut bending is due to joint eccentricities which were not modelled at the design stage. This effect was not observed with lower-scale physical models [23]. Compared with simulations cable stress reduction caused large deviations in nodal positions at the end of deployment

The total span of this $1 / 4$-scale structure is $4[\mathrm{~m}]$. The empty space inside the structure is intended for a pedestrian deck. The serviceability design criteria of the structure include limiting the vertical displacement at mid-span of the structure when the two bridge halves are connected and pre-stressed, as well as avoiding natural frequencies ranging from 1 to $4.5[\mathrm{~Hz}]$. Safety criteria involve limiting the internal forces below cable and spring tensile strength and below strut buckling loads when subject to ultimate load situations. The design study of the full-scale structure is presented in detail by Rhode-Barbarigos et. al. [27]. In addition, the authors have shown that the deployment is non-repeatable using the same control commands [23]. 
Figure 3 shows the mid-span connection prototype. This connection system consists of a cylinder with a cone shaped hole of $35[\mathrm{~mm}]$ internal radius and a rod with a round head (See Figure 4). Both pieces are made of steel and are connected to the joints of the structure. In addition, they are supported by small springs in order to maintain their horizontal orientation. After successful control commands are applied, the connection pieces are locked together with a pin that is introduced manually for economic reasons. This design of the connection is a first prototype made in order to develop and then test an active control methodology. In addition, after all five mid-span connections are completed, the degrees of freedom in the joint shall be locked in order to prevent relative movements between the ends of both bridge halves at mid-span. These degrees of freedom cannot be eliminated for connection. A connection joint with shorter length is the subject of future work.

\section{Numerical simulations}

Simulations of the structures are based on the dynamic relaxation method (DR) with kinetic damping by Barnes [30]. DR is a static analysis method in which the static equilibrium of a structure is calculated through solving a pseudo-dynamic problem using Newton's second law of motion. A fictitious inertia is applied to the structure and the oscillation of the structure is tracked. Oscillation is progressively damped using kinetic damping. Kinetic damping involves calculation of the kinetic energy and detection of kinetic energy peaks. When a peak is detected, the algorithm restarts with the nodal positions of the structure at the kinetic energy peak. Wakefield [31] stated that DR has been used successfully for hundreds of tent structures design and its computational efficiency has recently been shown by Resaiee-Pajand et. al. [32] and by Senatore and Piker [33] for pin-jointed and frame structures showing non-linear behavior. Most modern analysis software packages include DR modules. DR allows cable slackening and provides the final form of the structure as part of the output.

The influence of continuous cables on the mechanics of tensegrity structures was first described by Moored and Bart-Smith [29] under the term "clustered cables". Bel Hadj Ali et. al. [34] proposed a modified dynamic relaxation algorithm that is able to include clustered cables. This study employs this algorithm. 
Quasi-static actuation is assumed since deployment of the structure is slow and therefore, the inertia of the moving mass is not needed in simulations. The effect of a sequence of cable length change on the equilibrium state of the structure is simulated by a sequence of static analyses. In simulations, joints are assumed to be dimensionless and frictionless. In addition it is assumed that the self-weight is distributed at the extremities of elements as point loads.

A stochastic search algorithm is employed for obtaining initial control commands. The algorithm is called PGSL (probabilistic global search Lausanne) [35]. This algorithm searches for sets of better solutions assuming that they are in the neighborhood of previously evaluated sets of good solutions. The search process is guided by updating probabilities associated with regions of the solution space.

Control of the active tensegrity structure is a form of inverse non-linear engineering task where there is no closed-form solution that links a given control objective and the corresponding control command is available. Stochastic search algorithms are useful for obtaining good solutions for inverse engineering tasks such as design, diagnosis and control when exhaustive search is not feasible. PGSL has already been used successfully for various control tasks for an active tensegrity structures (Domer et. al. [5], Adam and Smith [36] and Korkmaz et. al. [37]) and performed as well or better than simulated annealing and genetic algorithms for several complex optimization tasks [35]. During the search for good control commands, each solution generated by the PGSL algorithm is evaluated with a DR simulation.

\section{Symmetric and uniform topologies for mid-span connection}

Two topologies (Figure 5), uniform (a) and symmetric (b), are compared. The topologies differ in terms of connectivity of elements and paths of continuous cables. In the uniform topology, the orientation of the second half is the same as that of the first. In the symmetric topology, the second half is a mirror image of the first half about the mid-span. These two topologies are compared in terms of serviceability and deployment behavior. When the bridge is connected and pre-stressed, all support nodes are blocked in the three directions of translation. During deployment and mid-span connection, support conditions are those indicated in Figure 2. 
All cable lengths and tensions are measured once manually on the structure when assembled. Cable lengths and tensions are used as input in DR simulations. Cable tensions are obtained from deformation measurements performed with a tool initially designed for estimation of tension in rigging cables of sailboat. When then the structure is deployed and prior to the first mid-span connection, the structure contains slack cables.

Figure 6 shows simulated positions of mid-span nodes of both bridge halves for a uniform topology. The positions are given in the y-z plane (see Figure 1) at the moment before the first mid-span connection. Results shown in Figure 4 are nodal positions simulated for measured cable stresses and lengths.

The mid-span nodes of both bridge halves describe the vertices of a pentagon. The center of the bridge-half-1 pentagon is shifted to the negative side of the $y$-axis while the center of the bridgehalf-2 pentagon is shifted to the positive side of the y-axis. The maximum distance between midspan nodes is $750(\mathrm{~mm})$. Such a distance, see Figure 6, creates a difficult mid-span connection challenge.

Unlike the uniform topology, simulation results show that centers of both bridge halves pentagons are shifted on the same side of the y-axis (Figure 7). This behavior is due to the symmetry of both bridge halves.

Figure 8 shows simulated (according to measured cable stresses) and measured positions of midspan nodes of the first bridge half. Figure 8 shows the discrepancy between simulations and measurements. This is likely due to the presence of joint eccentricities and friction on the near full-scale structure that is not modelled in the simulation. Measured values in Figure 8 show that the center of the pentagon is also shifted on the negative side of the y-axis. In addition, there is also a vertical shift.

Table 1 shows the distance determined by simulation and measurements between mid-span nodes at the moment before mid-span connection. The distance along the $\mathrm{x}$-axis is close to zero for the first mid-span connection. All other mid-span connection nodes have larger distances between them, particularly those of mid-span connection 3, 4 and 5 that are the lowest elevation nodes. This effect is due to the self-weight. This shows that a simultaneous connection is not a good 
strategy since a contact of the top of both bridge halves occurs before the distance between lowest elevation nodes is reduced.

Simulated static and dynamic characteristics of the uniform and symmetric topologies are given in Tables 2 and 3. Static and dynamic characteristics of the two topologies are compared since Rhode-Barbarigos et. al [27] identified stiffness related characteristics as critical design criteria. Natural frequencies are calculated based on a linearized dynamic model that is valid around equilibrium. The formulation of the stiffness matrix that takes into account mechanics of the continuous cables, is the one derived by Moored and Bart-Smith [29]. Table 2 shows the simulated vertical displacements of the mid-span nodes due to a service load for the uniform and symmetric topologies. Vertical displacements of the symmetric topology are smaller than those of the uniform topology except at node 4.

Table 3 shows that the simulated values of the first five natural frequencies are nearly the same for both topologies. The uniform and the symmetric topologies have similar serviceability behaviors. However, they result in different offset distances between mid-span nodes when measured cable stresses are considered. Thus, a symmetric topology is selected since it shows better performance for the mid-span connection.

\section{Computational control for mid-span connection}

This section describes the strategy for the connection at mid-span of the two bridge halves. No solution could be found for a simultaneous connection of all five mid-span joints since the distance between mid-span node pairs is non uniform. Thus, a sequential strategy for mid-span connection is studied, where each node is connected in series.

Figure 9 shows the flowchart of the control methodology for each mid-span connection. The initial control command (Figure 10) is applied incrementally on the structure so that no cable length change exceeds 10 [mm] during each increment. The position of the two mid-span nodes is measured after the application of each increment of the control command. The connection is performed when the distance between nodes is less than or equal to the length of the mid-span joint. If all increments have been applied and the connection cannot be done, the additional control command search starts (Figure 11). The number of additional control command required for one mid-span joint is not pre-defined and depends on nodal position measurements. In order 
to return to the cable length configuration prior to additional control command application, the sequence of additional control command is applied in the reverse order after the connection is locked. This process prevents the real cable lengths to deviate too much from the simulated lengths.

Figure 10 shows the flowchart for computing initial control commands for each mid-span connection. Assuming that the length change of active cables is between $-30[\mathrm{~mm}]$ and $80[\mathrm{~mm}]$ for the first mid-span connection, each cable can take 12 positions. Cable length changes smaller than $10[\mathrm{~mm}]$ result in non-significant nodal position changes. The size of the solution space is thus $12^{10}=6.210^{10}$ which corresponds to the number of combinations. Such a large solution space justifies the use of a stochastic search algorithm.

The variables of the stochastic search (PGSL) are the length changes of the ten active cables in both halves. Quasi-static simulations are performed to compute the positions of mid-span nodes for each solution (control command). These simulations are calculated with the dynamic relaxation algorithm under the assumption that joints are dimensionless and frictionless. The evaluation of each solution is based on the distance between a pair of mid-span nodes estimated according to the simulation result. The mid-span connection control task is stated as follows.

Objective function $=\sqrt[2]{\Delta_{y}^{2}+\Delta_{z}^{2}}+p_{1}+p_{2}$

Subject to constraints:

$\left|\sqrt[2]{\Delta_{y}^{2}+\Delta_{z}^{2}}-30\right|<0$

$\left|\Delta_{x}-L_{\text {joint }}\right|<5$

When constraint [2] is not satisfied, a penalty value $p_{1}$ is added following equations [4].

$p_{1}=10 \cdot\left(1+\left|\sqrt[2]{\Delta_{y}^{2}+\Delta_{z}^{2}}-30\right|\right)$

Similarly when constraint [3] is not satisfied, a penalty value $p_{2}$ is added following equations [5].

$p_{2}=10 \cdot\left(1+\left|\Delta_{x}-L_{\text {joint }}\right|\right)$ 
In these equations, $\Delta_{x}, \Delta_{y}$ and $\Delta_{z}$ are the distances in $[\mathrm{mm}]$ along the $\mathrm{x}, \mathrm{y}$ and $\mathrm{z}$ axes between the two joining nodes. The values $p_{1}$ and $p_{2}$ are penalty values applied when constraints are not satisfied. The constant $L_{\text {joint }}$ is the length of a mid-span joint and the values of 5 and 30 [mm] in equations [2] and [3] are tolerance values related to the geometry of the mid-span joint prototype. Figure 11 show the evolution of the objective function when computing the initial control command for the second mid-span joint. Solutions found before 100 iterations do not satisfy the constraints and results in a large objective function value.

After the stochastic search, the mid-span nodes are linked in the simulation model according to the best solution found. The configuration of the structure with the new mid-span connection is computed by dynamic relaxation. This configuration of the simulated structure is used as an input for the computation of the next mid-span connection. When an initial control command is applied on the near full-scale structure, the distance between the two parts of the joints is reduced and for mid-span joints 1, 2, 4 and 5, the rod enters inside the hollow cylinder.

In the case where initial control commands do not result in a successful connection, additional control commands are required. The additional control command search is based on node position measurement after application of active cable length changes. Nodal positions are measured using an optical tracking system that captures the position and orientation of markers attached to the two parts of the mid-span joints. The search for additional control command starts by checking the distance between nodes (Figure 12).

If the remaining distance along the $\mathrm{x}$-axis between both connection pieces is less than 10 [mm], the centering of the rod connection piece is checked in order to ensure that the rod will enter inside the cone hole of the cylinder connection piece. Depending on the remaining distance between connection pieces and centering (geometric criterion), the additional control command is the length change of either one or two active cables. In the case of two active cables, there is one cable on both halves and they end at the same mid-span connection. Therefore they are called pairs of symmetric cables, see Figure 12.

Aside from the fact that the additional control commands consist of one or two active cables, the search process is the same. First a 10 [mm] length change of one or two active cables is applied and the effect on the distance between connection pieces is measured. A cable length change of 
$10[\mathrm{~mm}]$ results in a relative position change between the two parts of a mid-span joint that do not exceeds $5[\mathrm{~mm}]$ in the y and $\mathrm{z}$ plan (see Figure 3.1). Using small cable length changes prevent situations where a back process is required when alignment is not satisfied.

Then a reverse cable length change is applied and another active cable or pair of symmetric cables is tested. This three step process is repeated for all single cables or pair of symmetric cables. The active cable or the pair of symmetric cables resulting in the smallest connection distance is selected as the additional control command.

Figure 13 shows the length change of active cables of each bridge half for the five mid-span connections. The initial control commands are searched using measured values of cable lengths and stresses obtained once following assembly of the structure. They are shown in black and the additional control commands in grey.

Figure 13 shows the length changes of active cables of each bridge half for the five mid-span connections. The initial control commands are shown in black and the additional control command in grey. Results in Figure 13 indicate that control commands follow similar patterns for both halves of the footbridge. For each mid-span connection event, active cable length changes are always of the same sign for each pair of active cable (active cable 1 in bridge half 1 and active cable 1 in bridge half 2). However, the magnitudes of cable length changes are not always the same. The differences between cable length changes applied for the mid-span connection of the two bridge halves is explained by differences between the two bridge halves. The vertical position of the five supports is $35[\mathrm{~mm}]$ higher on Bridge Half 2 than on Bridge Half 1 . This difference could be representative of construction error or settlement of a support.

The difference in support height is taken into account in DR simulations. Cable lengths of both bridge halves are set to be the same. However a $+-1[\mathrm{~mm}]$ measurement error when length of the cable is set is likely to occur. This error would be less significant on a full-scale structure since the element length would be four times larger while cable length set error would likely stay the same. Support-height differences and inaccuracies of cable-length settings mean that the two bridge halves do not have identical initial control commands.

The first mid-span connection is successfully executed without requiring additional control commands. The second and third connections require additional control commands. The fourth 
mid-span connection is successfully executed without requiring additional control commands while the fifth connection requires a few additional control commands.

Additional control commands are required when simulations deviate from the real behavior of the near full-scale model. According to Figure 13, discrepancies between the real behavior and simulations increase from the first mid-span connection to the third one. After the third mid-span connection, that is the mid-span connection event that requires the most additional control commands, discrepancies are reduced.

A minority of mid-span connection events are successfully executed without requiring additional control commands. This is due to the joint eccentricities and friction effects that are neglected in the simulations. Despite the simplifying assumptions of the simulation, initial control commands provide good initial solutions that are successfully completed with additional control commands. The additional control commands are efficient since they are based on real-time nodal position measurements.

Figure 14 shows a top view of mid-span connection events. The offset distances between corresponding mid-span nodes can be seen in Figure 14. The distances between lower mid-span nodes are more than those at the top because of the deformation due to self-weight. In addition, the deviation between mid-span nodes become larger after mid-span connection 2 is carried out. After each mid-span connection, the behavior of the footbridge changes.

\section{Discussion}

A uniform topology would have been an attractive choice without observation of nodal positions of the structure in the deployed state. The advantages of the symmetric topology are only visible after performing tests on a near full-scale structure.

Although a previous study by the authors [23] has shown that the deployment behavior cannot be modelled with the assumption of dimensionless frictionless joints, modelling of joints is time consuming. Work that attempted to model joint more accurately lead to excessive computation time and only small accuracy improvements. Control command search is associated with a long execution times since quasi-static simulations are performed in order to evaluate each stochastic solution. This research has shown that combining simplified computational control (involving 
simulation of the structure based on simplifying assumptions related to joint dimension and friction) with real-time measurements of the structural response leads to successful outcomes.

The use of real-time measurements of the structural response is a strategy that is also justified since the nodal position varies from one instance of deployment to another. Additional control commands are searched again at each instance of connection of the two bridge halves in order to accommodate the non-repeatability of deployment. However this process is slow and a strategy to re-use previous additional control commands is a subject of future work to improve the mid-span connection process. In addition there are cables that remain slack after connection of the five mid-span joints. Finding control commands for pre-stressing the whole structure after the connection at mid-span is also a subject of future work.

Implementation of this active deployable tensegrity structure at full-scale would involve challenges related to unknown environment conditions. Temperature effects will have an effect on the self-stress of the structure and thus modify its deployment behavior. Such changes in external conditions further justify the need for active control.

This study contributes to advancing the field of active tensegrity structure primarily since few full-scale structures have been built and tested. The active-control methodology is an extension of static control to large shape changes that are necessary for deployment. In addition this structure includes several special features, such as active cables that are continuous over joints, spring elements and rail supports, that facilitate deployment. It is expected that a full-scale implementation of a complex deployable structures would benefit from at least one of these features.

\section{Conclusions}

Symmetric topologies lead to successful mid-span connection of ring-module tensegrity footbridges. Symmetric and uniform topologies have a similar serviceability performance in terms of mid-span displacement and natural frequencies. Active control strategies provide effective solutions for mid-span connection. Initial control-command solutions generated using simulations that include assumption of dimensionless and frictionless joints are not accurate enough to complete all five physical mid-span connections. Additional control search leads to successful mid-span connection. Additional control commands are determined successfully through nodal position measurement on the structure in real-time. 
Future work will involve designing a robust control methodology to speed up mid-span connections, to pre-stress the structure after connection and to accommodate changing environments, damage and in-service response.

\section{Acknowledgments}

Authors are thankful to the Swiss National Science Foundation for supporting this work through contract number 200020_144305. This work builds on a study that was begun in collaboration with Professor René Motro, University of Montpellier, France. Finally we thank the technicians (P. Gallay, C. Gilliard and G. Guignet) for their contributions.

\section{References}

[1] Motro, R. (2003). Tensegrity: structural systems for the future. London: Kogan Page Science

[2] Skelton, R.E., and De Oliveira, M.C., (2009). Tensegrity systems, Springer

[3] Caluwaerts, K., and Carbajal, J.P., (2015). Energy conserving constant shape optimization of tensegrity structures, International Journal of Solids and Structures, 58, 117-127.

[4] Ziegler, F. (2005). Computational aspects of structural shape control. Computers and Structures, 83(15-16), 1191-1204.

[5] Domer, B., Raphael, B., Shea, K., and Smith, I. F. C. (2003). A study of two stochastic search methods for structural control. J. Comput. Civ. Eng., 17(3), 132-141.

[6] Adam, B., and Smith, I. F. C. (2008). Reinforcement learning for structural control. Journal of Computing in Civil Engineering, 22(2), 133-139.

[7] Dalil Safaei, S., Eriksson, A., and Tibert, G. (2012). Improving the bending stiffness of tensegrity booms. International Journal of Space Structures, 27(2-3), 117-130.

[8] Shon, S., Kwan, A.S., Lee, S. (2014) Shape control of cable structures considering concurrent/sequence control. Structural Engineering and Mechanics, 52(5), 919-935.

[9] Kmet, S., Platko, P. (2014). Adaptive tensegrity module. II: tests and comparison of results, Journal of Structural Engineering, 140 (9).

[10] Ganesh Raja M., Narayanan S. (2007). Active control of tensegrity structures under random excitation. Smart Materials and Structures. 16, 809-17.

[11] Bel Hadj Ali, N., and Smith, I.F.C. (2010). Dynamic behavior and vibration control of a tensegrity structure International Journal of Solids and Structures, 47(9), 1285-1296.

[12] El Ouni, M.H., Ben Kahla, N. (2014). Active tendon control of a Geiger dome. Journal of Vibration and Control. 20(2), 241-255. 
[13] Amouri, S., Averseng, J., Quirant, J., Dube, J.-F. (2014). Structural design and control of modular tensegrity structures. European Journal of Environmental and Civil Engineering. (In press)

[14] Graells Rovira, A., and Mirats Tur, J. M. (2009). Control and simulation of a tensegritybased mobile robot. Robotics and Automous Systems, 57(5), 526-535.

[15] Caluwaerts, K., Despraz, J., Işçen, A., Sabelhaus, A.P., Bruce, J., Schrauwen, B., SunSpiral, V. (2014). Design and control of compliant tensegrity robots through simulation and hardware validation, Journal of the Royal Society Interface, 11 (98).

[16] Bliss, T., Iwasaki, T., Bart-Smith, H. (2013). Central pattern generator control of a tensegrity swimmer. IEEE/ASME Transactions on Mechatronics, 18 (2), 6291790, 586597

[17] Pinaud, J.-P., Solari, S., Skelton, R.E. (2004). Deployment of a class 2 tensegrity boom, Proceedings of SPIE - The International Society for Optical Engineering, San Diego, California.

[18] Schenk, M., Guest, S.D., Herder, J.L. (2007). Zero stiffness tensegrity structures, International Journal of Solids and Structures, 44, 6569-6583.

[19] Zolesi, V. S., Ganga, P. L., Scolamiero, L., Micheletti, A., Podio-Guidugli, P., Tibert, G., and Ghiozzi, M. (2012). On an innovative deployment concept for large space structures, Proceedings of 42nd International Conference on Environmental Systems, San Diego, California, USA.

[20] Zhang, P., Kawaguchi, K., Feng, J. (2014). Prismatic tensegrity structures with additional cables: Integral symmetric states of self-stress and cable-controlled reconfiguration procedure. International Journal of Solids and Structures, 51(25-26), 4294-4306.

[21] Xu, X., Sun, F., Luo, Y., and Xu, Y. (2014). Collision-free path planning of tensegrity structures. Journal of Structural Engineering, 140(4), 04013084.

[22] Sultan, C. (2014). Tensegrity deployment using infinitesimal mechanisms, International Journal of Solids and Structures, 51(21-22), 3653-3668.

[23] Veuve, N., Dalil Safaei, S., and Smith I.F.C. (2015). Deployment of a tensegrity footbridge, Journal of Structural Engineering, 141(11). 04015021

[24] Pugh, A., (1976). An introduction to tensegrity. University of California Press, Berkley, CA.

[25] Motro, R., Maurin, B., and Silvestri, C. (2006). Tensegrity rings and the hollow rope, IASS Symposium, New Olympics, New Shells and Spatial Structures, Beijing, China.

[26] Cevaer, F., Quirant, J., Dubé, J.F. (2012) Mechanical behaviour in compression of a foldable tensegrity ring: parametric study and rheological model.International Journal of Space Structures, 27(2), 107-115.

[27] Rhode-Barbarigos, L., Bel Hadj Ali, N., Motro, R., and Smith I.F.C. (2012). Design aspects of a deployable tensegrity-hollow-rope footbridge, International Journal of Space Structures, 27(2), 81-96. 
[28] Rhode-Barbarigos. L., Schulin. C., Bel Hadj Ali, N., Motro, R., and Smith I.F.C. (2012). Mechanism-based approach for the deployment of a tensegrity-ring module. Journal of Structural Engineering, 138(4), 539-548.

[29] Moored, K.W. and Bart-Smith H. (2009). Investigation of clustered actuation in tensegrity structures, International Journal of Solids and Structures, 46(17), 3272-3281.

[30] Barnes, M.R. (1999). Form finding and analysis of tension structures by dynamic relaxation. International Journal of Space Structures. 14, 89-104.

[31] Wakefield, D. S. (1999). Engineering analysis of tension structures: theory and practice. Engineering structures, 21(8), 680-690.

[32] Rezaiee-Pajand, M., Sarafrazi, S. R., \& Rezaiee, H. (2012). Efficiency of dynamic relaxation methods in nonlinear analysis of truss and frame structures. Computers \& Structures, 112, 295-310.

[33] Senatore, G., \& Piker, D. (2015). Interactive real-time physics: an intuitive approach to form-finding and structural analysis for design and education. Computer-Aided Design, 61, 32-41.

[34] Bel Hadj Ali, N., Rhode-Barbarigos, L., and Smith I.F.C. (2011). Analysis of clustered tensegrity structures using a modified dynamic relaxation algorithm. International Journal of Solids and Structures. 48(5), 637-647.

[35] Raphael, B., and Smith, I. F. C. (2003). A direct stochastic algorithm for global search, Applied Mathematics and Computation, 146(2-3), 729-758.

[36] Adam, B., \& Smith, I. F. (2007). Tensegrity active control: Multiobjective approach. Journal of Computing in Civil Engineering, 21(1), 3-10.

[37] Korkmaz, S., Ali, N. B. H., \& Smith, I. F. (2012). Configuration of control system for damage tolerance of a tensegrity bridge. Advanced Engineering Informatics, 26(1), 145155. 
Table 1: Distances [mm] determined by simulation and measurement between mid-span nodes of both bridge halves at the moment before mid-span connection

\begin{tabular}{|c|c|c|c|c|c|}
\hline Node & $\begin{array}{c}\text { Assessment } \\
\text { type }\end{array}$ & $\begin{array}{c}\text { distance } \\
\text { along } \mathrm{X} \\
\text { axis }\end{array}$ & $\begin{array}{c}\text { distance } \\
\text { along y } \\
\text { axis }\end{array}$ & $\begin{array}{c}\text { distance } \\
\text { along } \mathrm{z} \\
\text { axis }\end{array}$ & $\begin{array}{c}\text { distance } \\
{[\mathrm{mm}]}\end{array}$ \\
\hline \multirow{2}{*}{1} & Simulation & 25 & -8 & 38 & 46 \\
\hline & Measurement & 31 & 33 & -30 & 54 \\
\hline \multirow{2}{*}{2} & Simulation & 30 & 1 & 57 & 65 \\
\hline & Measurement & 113 & 30 & 35 & 122 \\
\hline \multirow{2}{*}{3} & Simulation & 208 & 24 & 60 & 218 \\
\hline & Measurement & 346 & 61 & 30 & 353 \\
\hline \multirow{2}{*}{4} & Simulation & 235 & 32 & 25 & 238 \\
\hline & Measurement & 366 & 64 & 10 & 372 \\
\hline \multirow{2}{*}{5} & Simulation & 239 & 15 & 13 & 240 \\
\hline & Measurement & 326 & 52 & -15 & 330 \\
\hline
\end{tabular}

Table 2: Simulated vertical displacements of the five mid-span nodes subjected to service loading

\begin{tabular}{ccc}
\hline \multicolumn{3}{c}{ Vertical displacement (mm) } \\
\hline Node number & Uniform topology & Symmetric topology \\
\hline 1 & 9 & 9 \\
2 & -5 & -4 \\
3 & -10 & -9 \\
4 & -10 & -12 \\
5 & -7 & -2 \\
\hline
\end{tabular}


Table 3: Simulated first five natural frequencies of a footbridge with uniform and symmetric topologies

\begin{tabular}{cc}
\hline \multicolumn{2}{c}{ Natural frequency $(\mathrm{Hz})$} \\
\hline Uniform topology & Symmetric topology \\
\hline 7.4 & 7.3 \\
9.5 & 9.6 \\
10.3 & 10.3 \\
12.3 & 12.0 \\
12.8 & 12.3 \\
\hline
\end{tabular}


List of figures

Figure 1: Top view of (a) folded structure showing the numbering of mid-span nodes and (b) deployed structure connected at mid-span as well as $\mathrm{x}, \mathrm{y}$ and $\mathrm{z}$ conventions.

Figure 2: Support orientation during deployment and mid-span connection

Figure 3: Mid-span connection prototype, (a) before connection (b) after connection

Figure 4: Section view of the cylinder with the cone shaped hole and the rod (See Figure 3 (a) and (b))

Figure 5: Plan view of (a) uniform and (b) symmetric topologies showing the strut network and one of five continuous cables.

Figure 6: Simulated positions of the mid-span nodes after deployment for a uniform topology (Figure 5(a)). Simulated nodal positions are obtained according input values that are cable stresses and lengths measured after the assembly.

Figure 7: Simulated positions of the mid-span nodes after deployment for a symmetric topology (Figure 5(b)). Positions are calculated according to measured cable stresses measured at the moment before mid-span connection.

Figure 8: Position of mid-span nodes of the first bridge half determined by simulation (according to measured cable stresses) and direct position measurements

Figure 9: Flowchart of the control methodology for executing mid-span connection using realtime node-position measurements

Figure 10: Flowchart for computing initial control commands using dynamic relaxation

Figure 11: Convergence curve of the objective function value when computing the initial control command for the second mid-span joint.

Figure 12: Additional control-command-search flowchart

Figure 13: Initial (Figure 10) and additional (Figure 12) control commands of each bridge half for the five mid-span connection events

Figure 14: Top view of mid-span connection events 

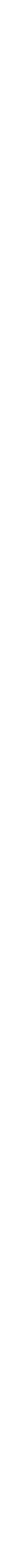

.

政

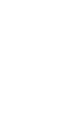


Figure_2

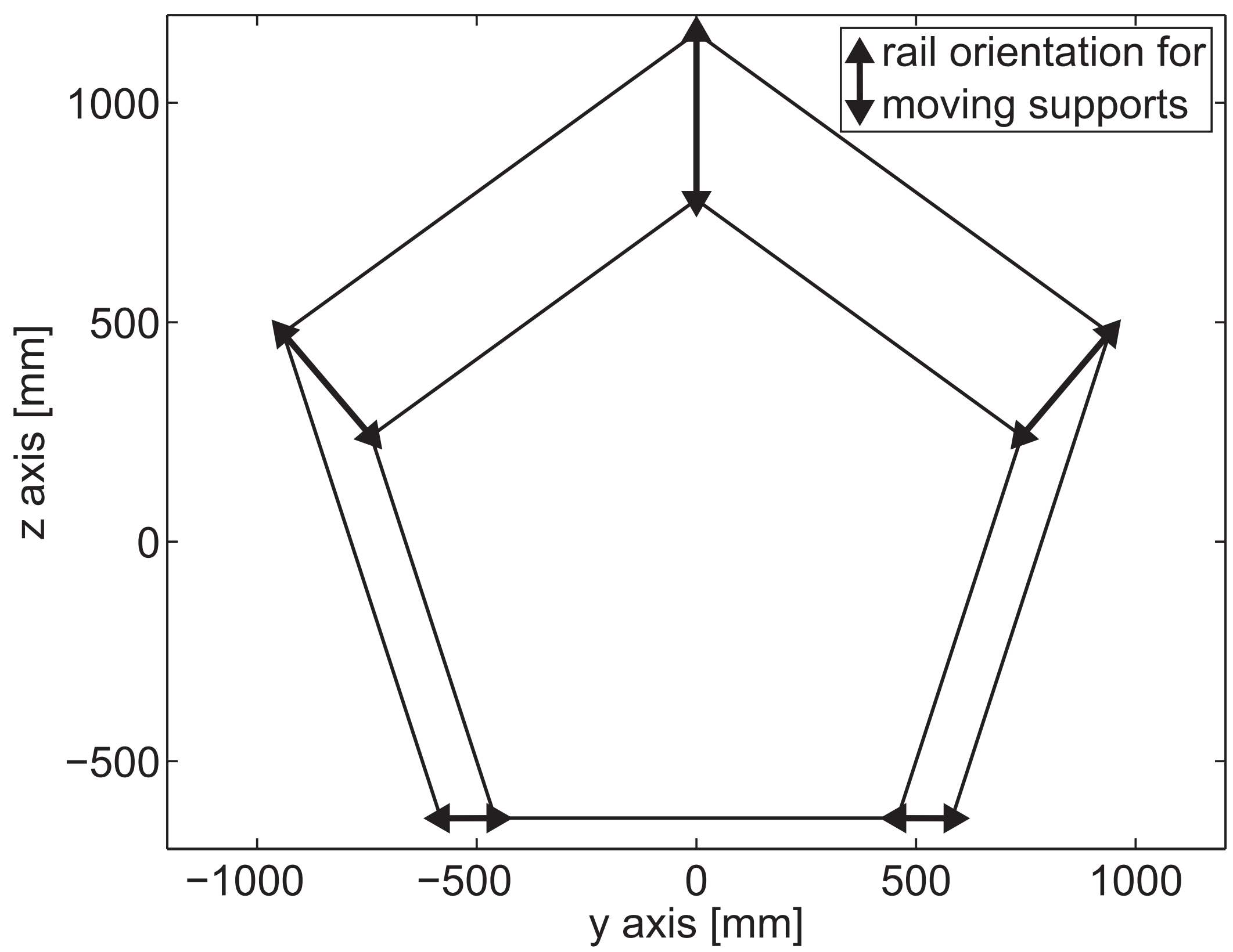




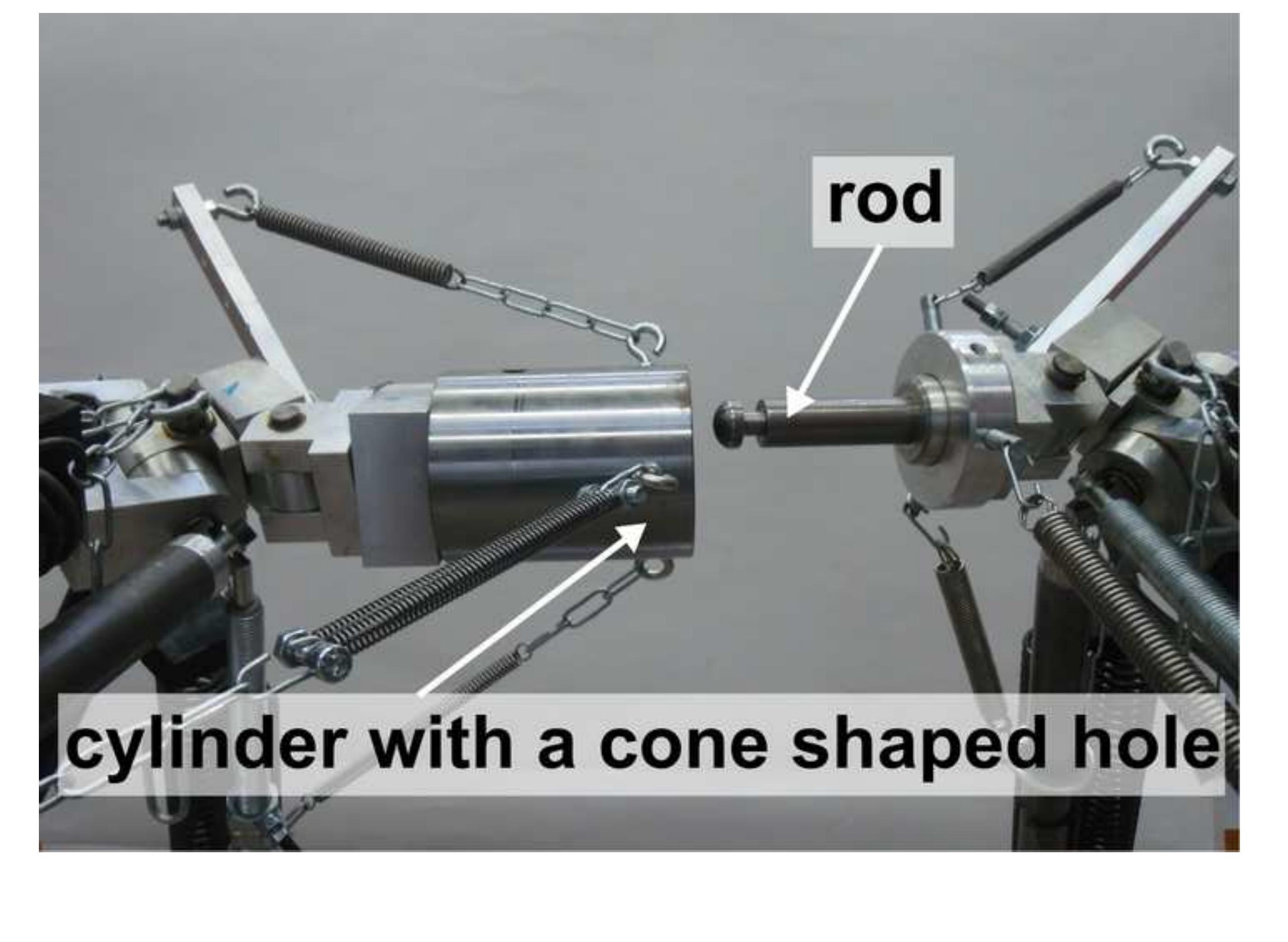




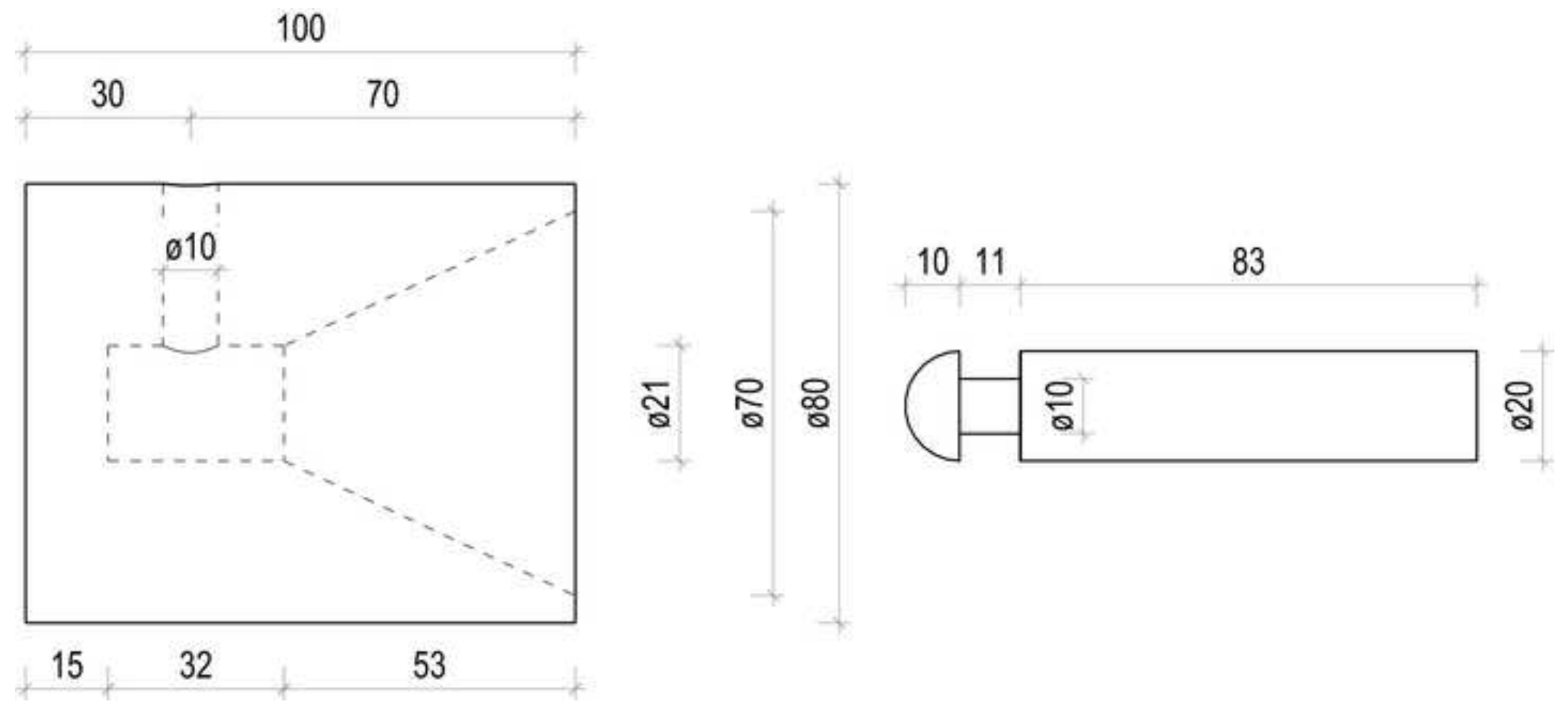




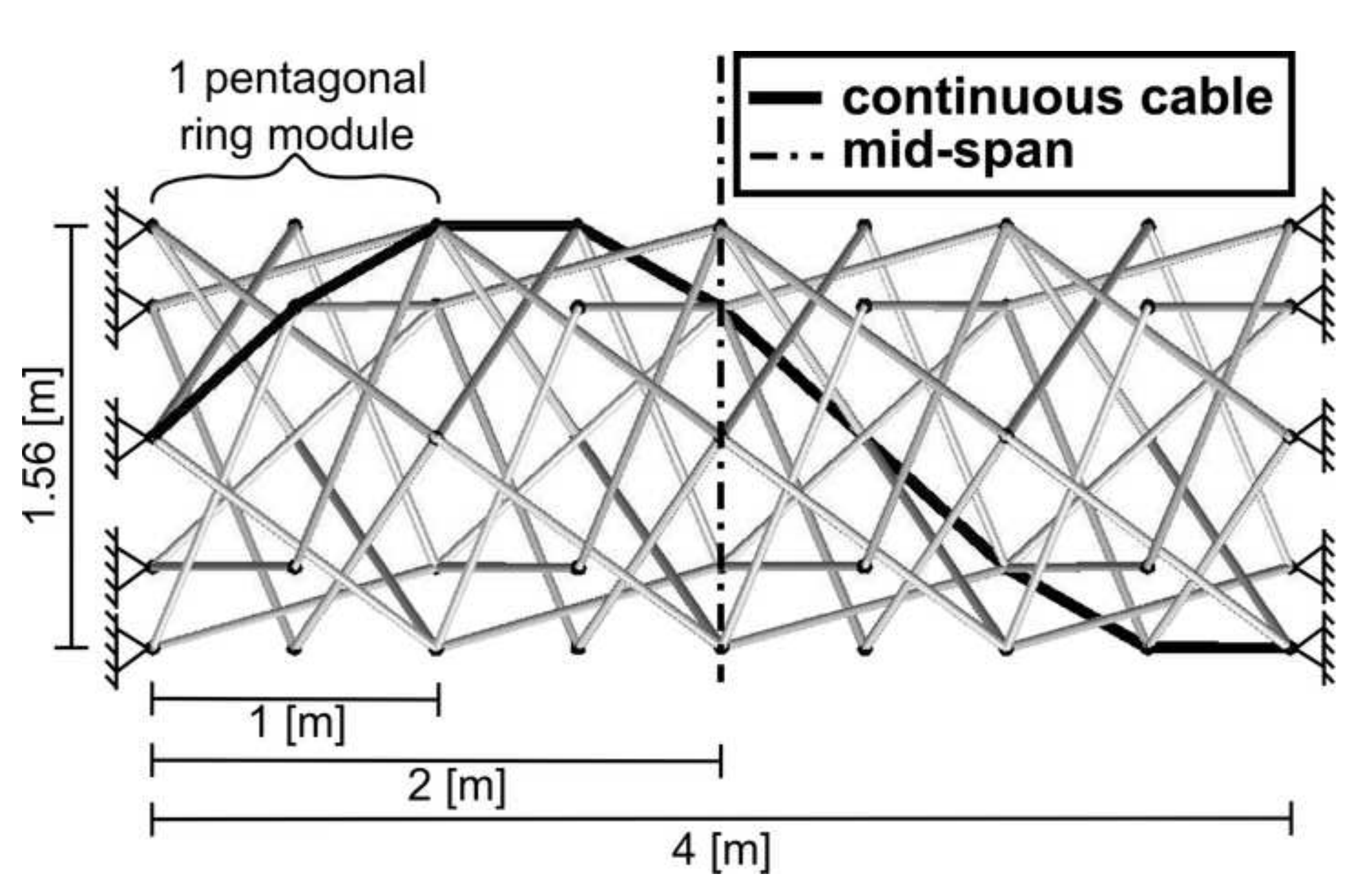

1 pentagonal 


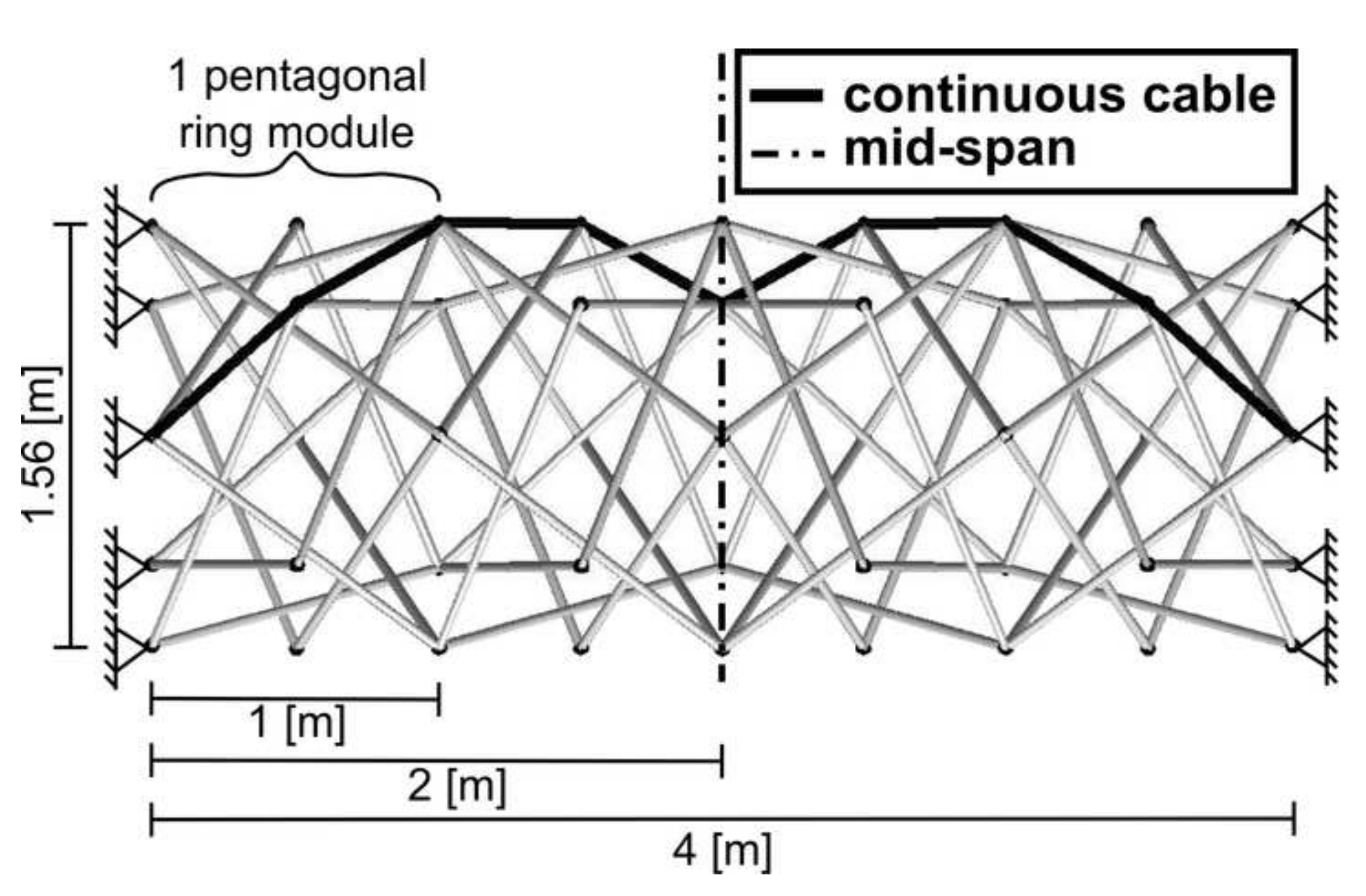

1 pentagonal 


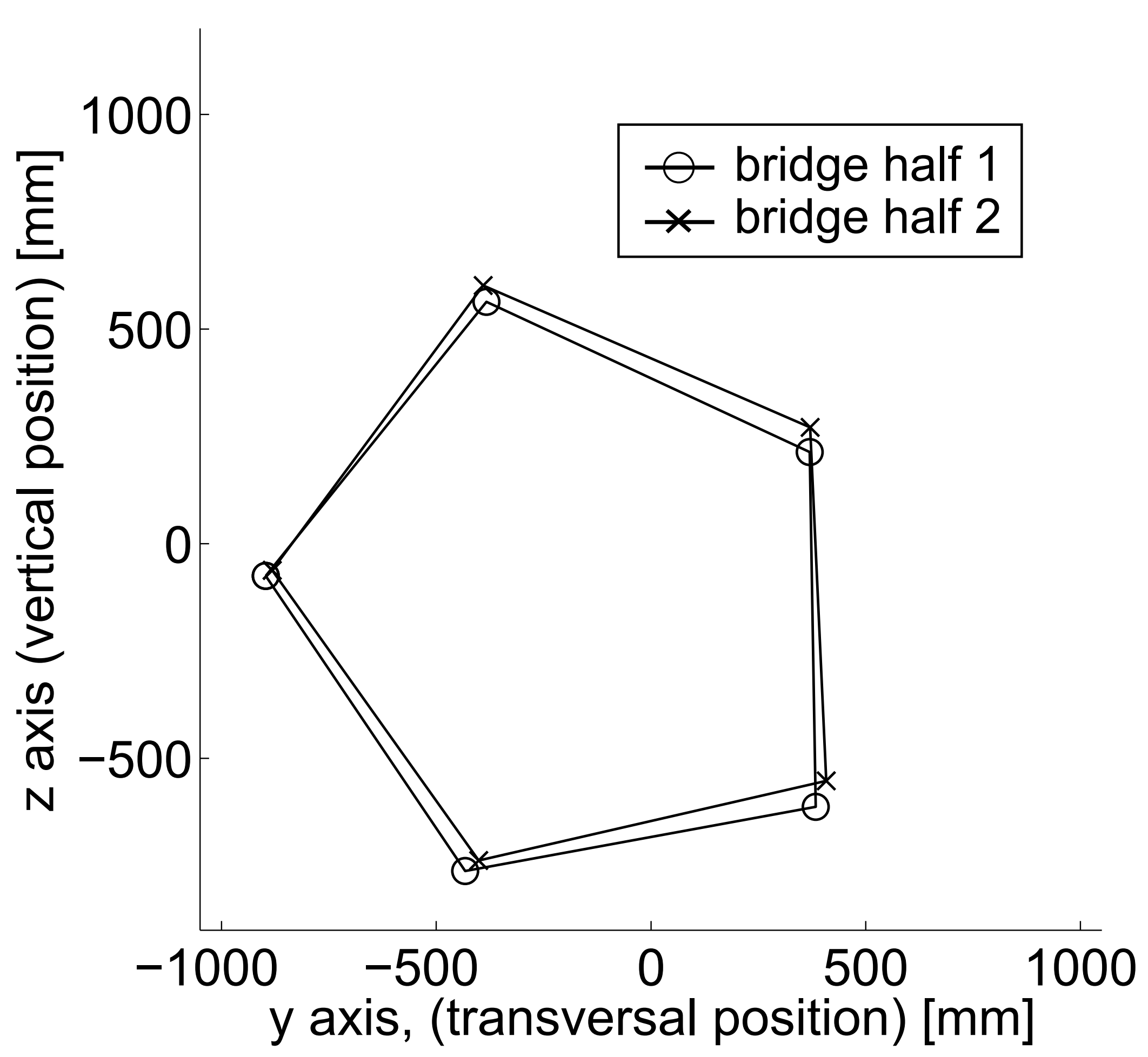

Figure_7

\section{$\oslash$ bridge half 1 \\ $*$ bridge half 2}

\section{y axis, (transversal position) [mm]}




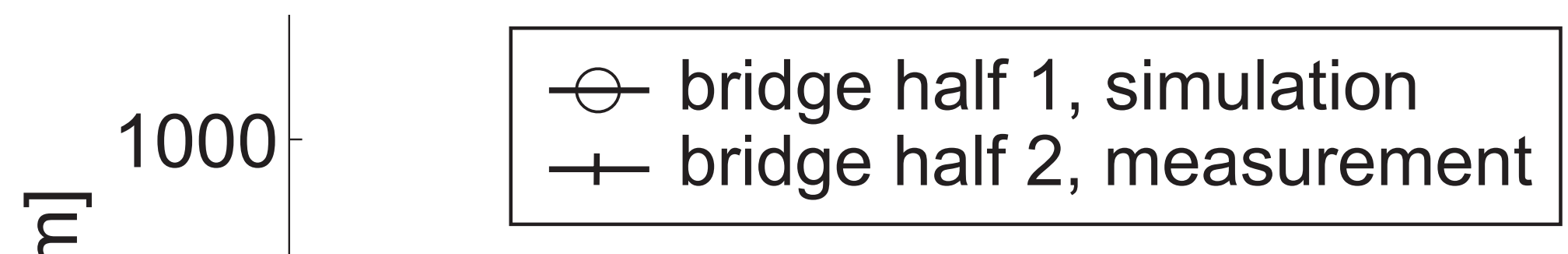

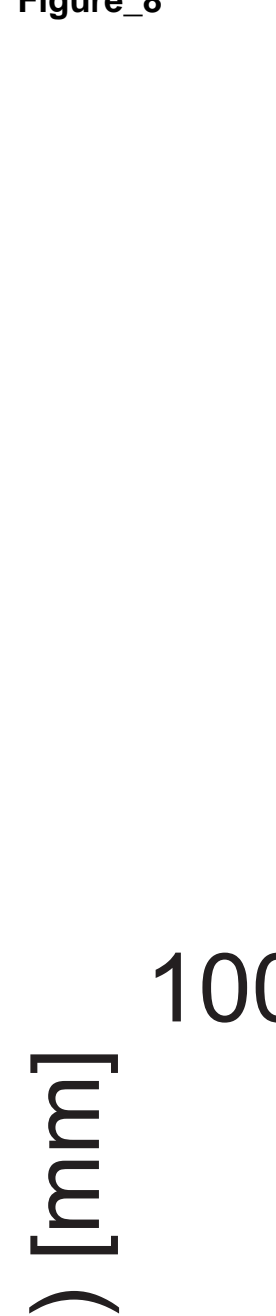
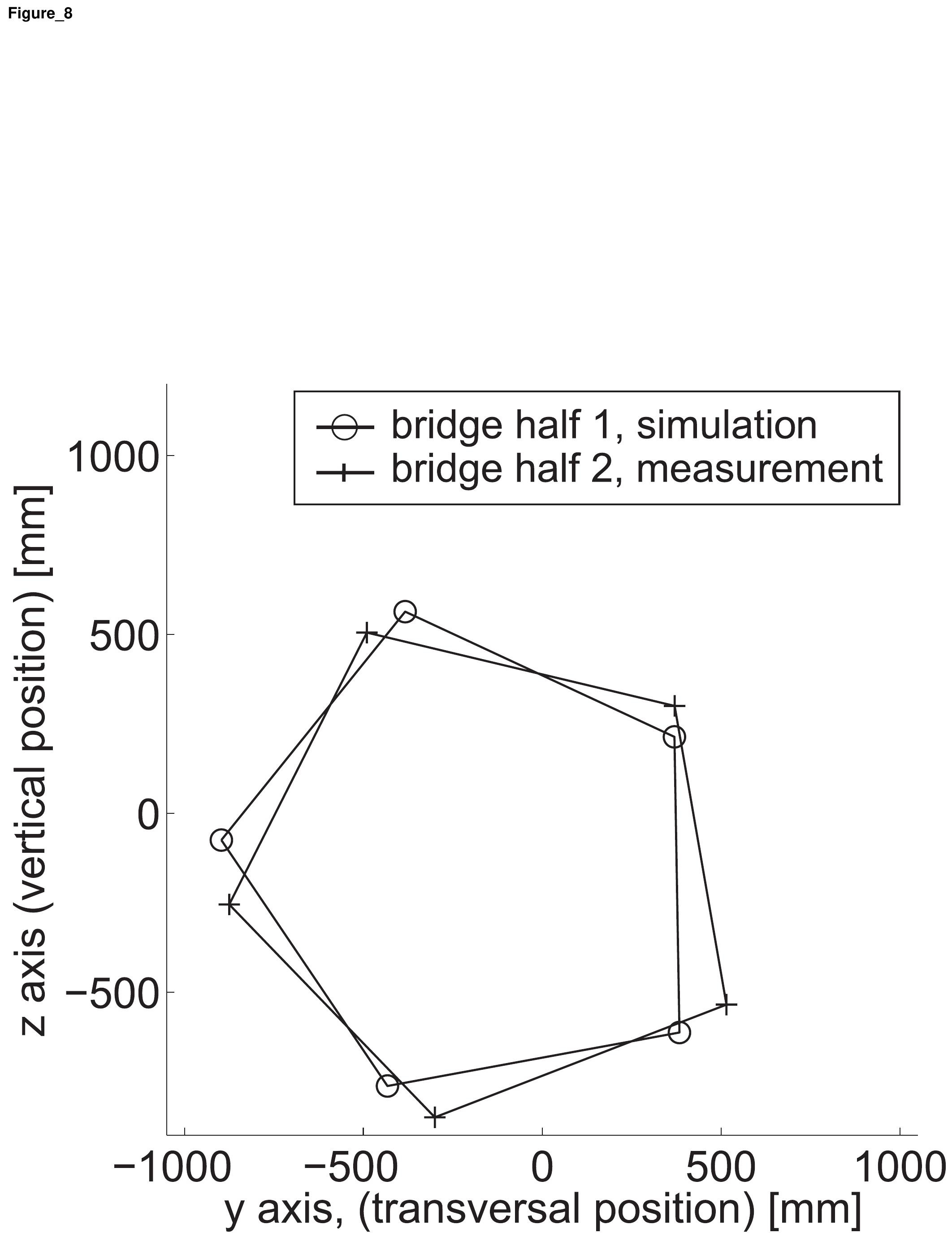

\section{y axis, (transversal position) [mm]}

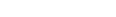

\section{$\ominus$ bridge half 1 , simulation
+ bridge half 2 , measurement \\ $\ominus$ bridge half 1 , simulation
+ bridge half 2 , measurement}

2 
Initial control command search for connection of the five mid-span joint (See Figure 10)

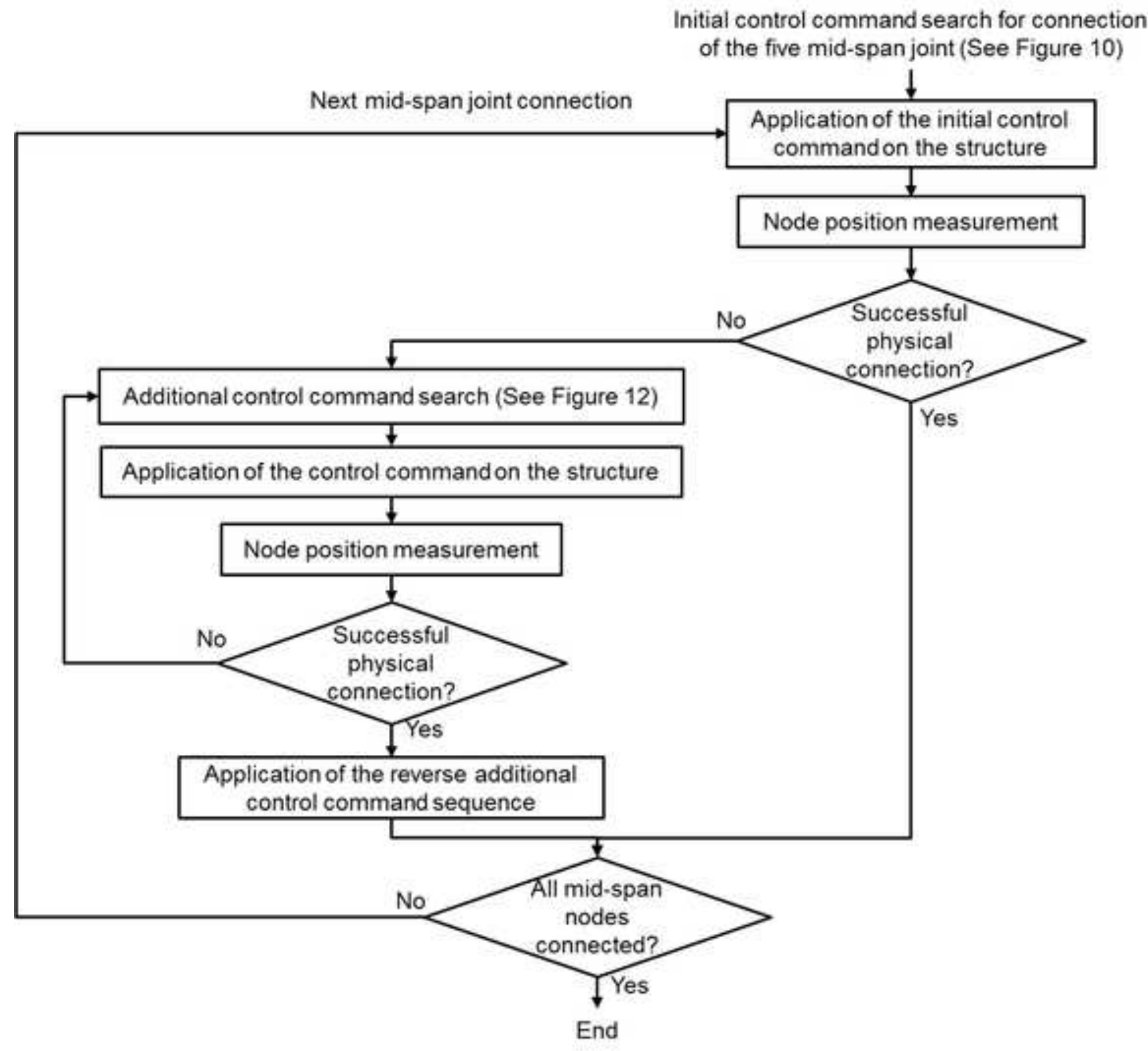


Starting information:

Topology

Nodal coordinates

Axial stiffness of elements

Self-weight loading

Measured cable stresses and lengths

(measured after assembly of the structure)

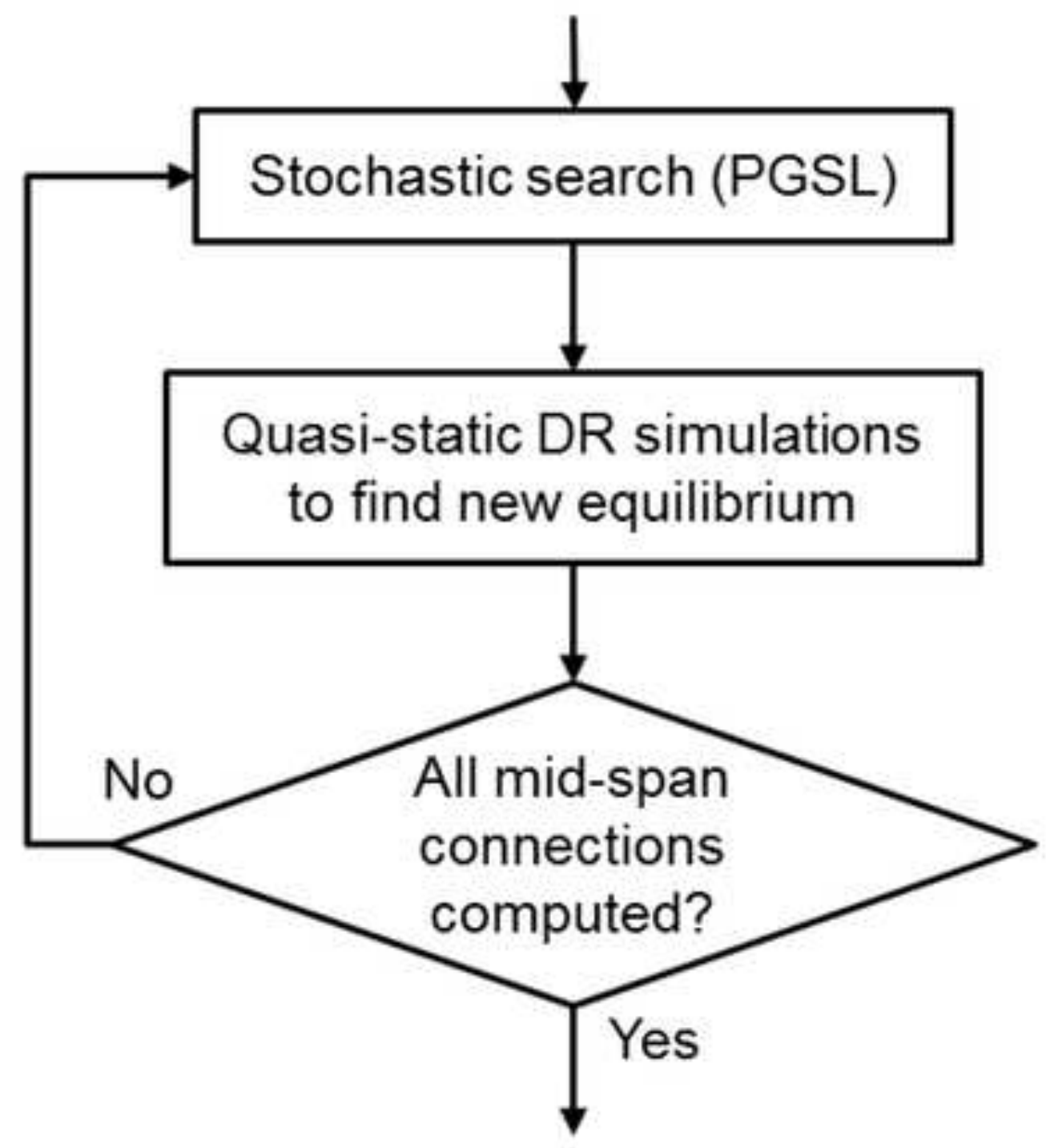

Figure 9 
Figure_11
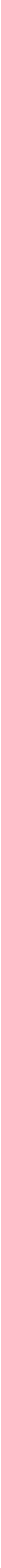


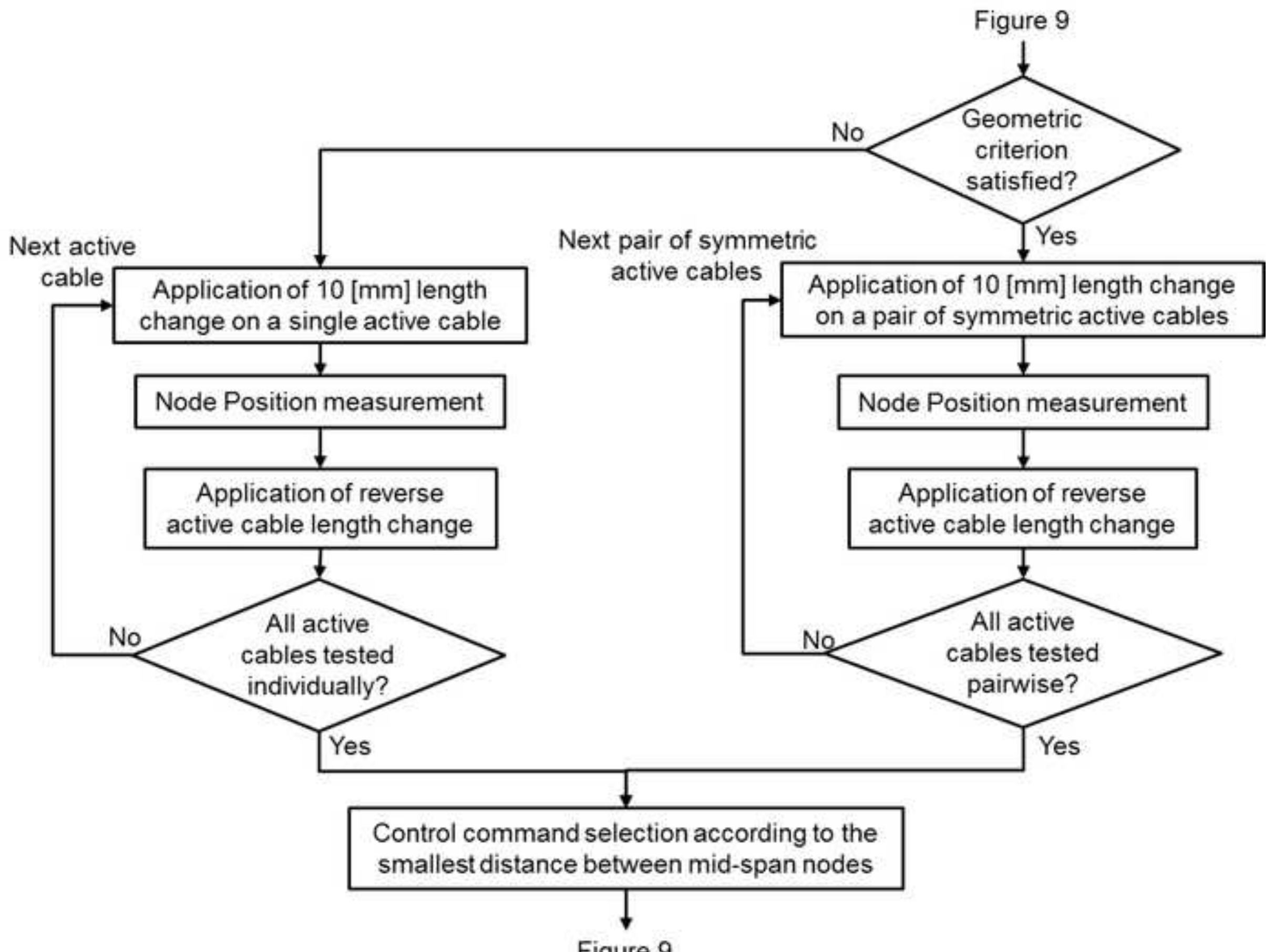

igure 9

criterion

satisfied?

Figure 9

ext active

(a)

Node Position measurement

Application of reverse

ctive cable length change

All active

ables tested

individually?

Yes

Control command selection according to the

smallest distance between mid-span nodes 
Mid-span connection1

bridge half 1

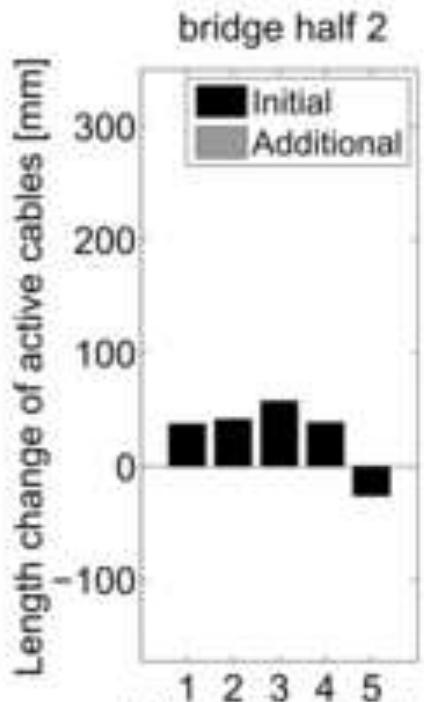

$\begin{array}{ccccc}1 & 2 & 3 & 4 & 5 \\ \text { Active cable number }\end{array}$ Active cable number

Mid-span connection 3

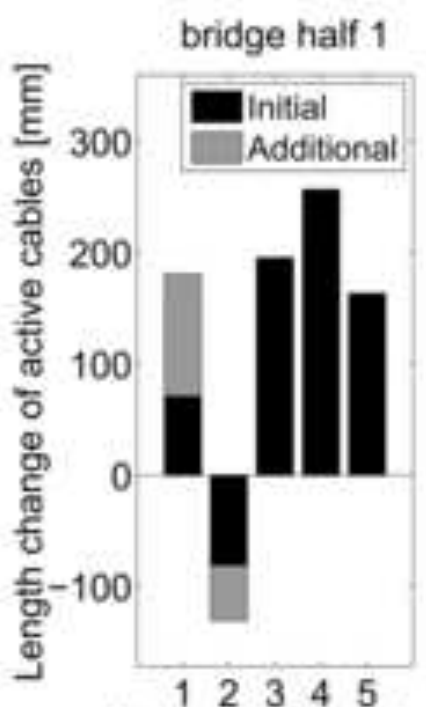

Active cable number

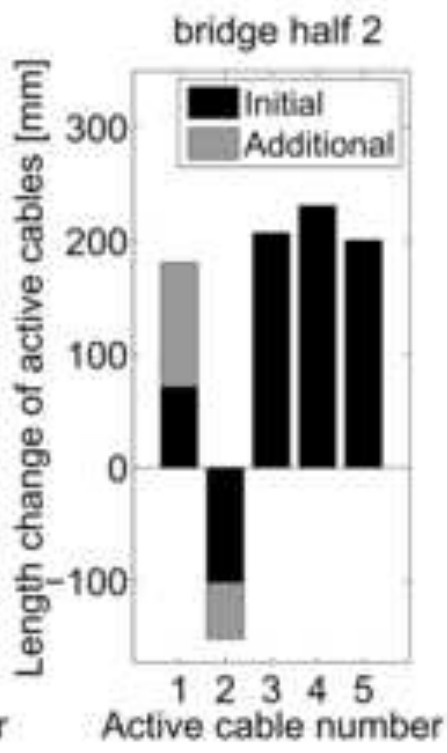

Mid-span connection 5

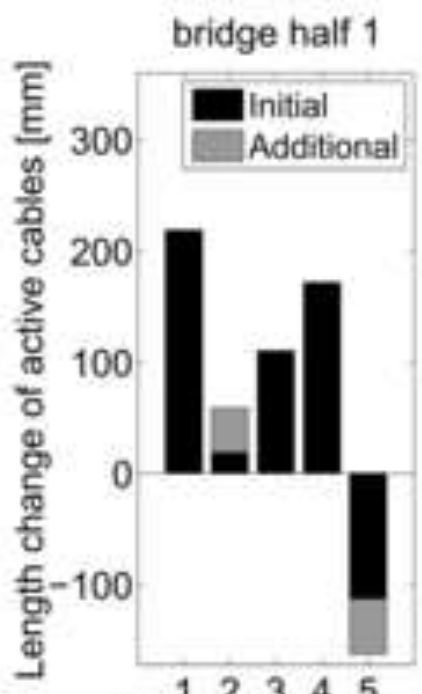

122345

Active cable number

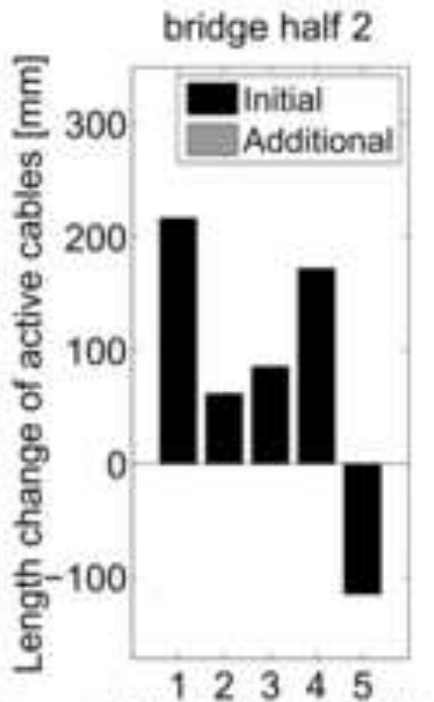

Active cable number
Mid-span connection 2

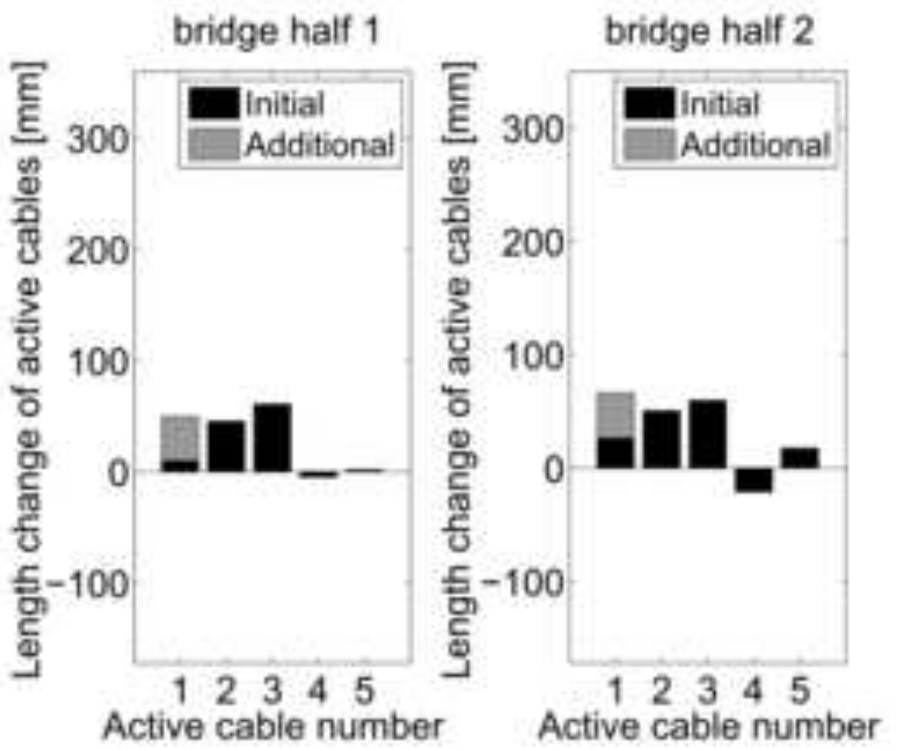

\section{Mid-span connection 4}

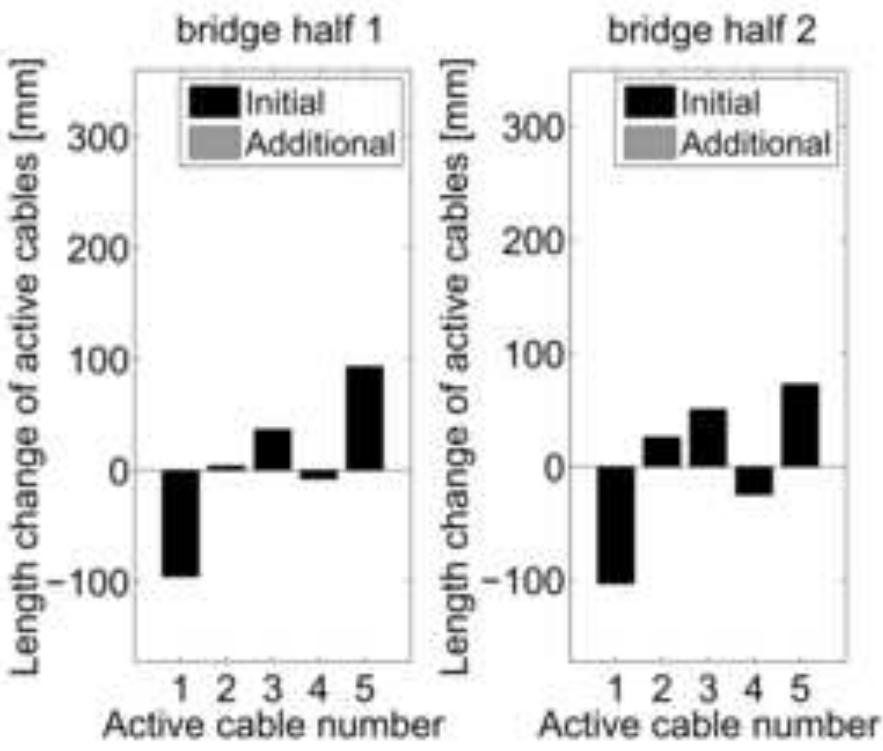



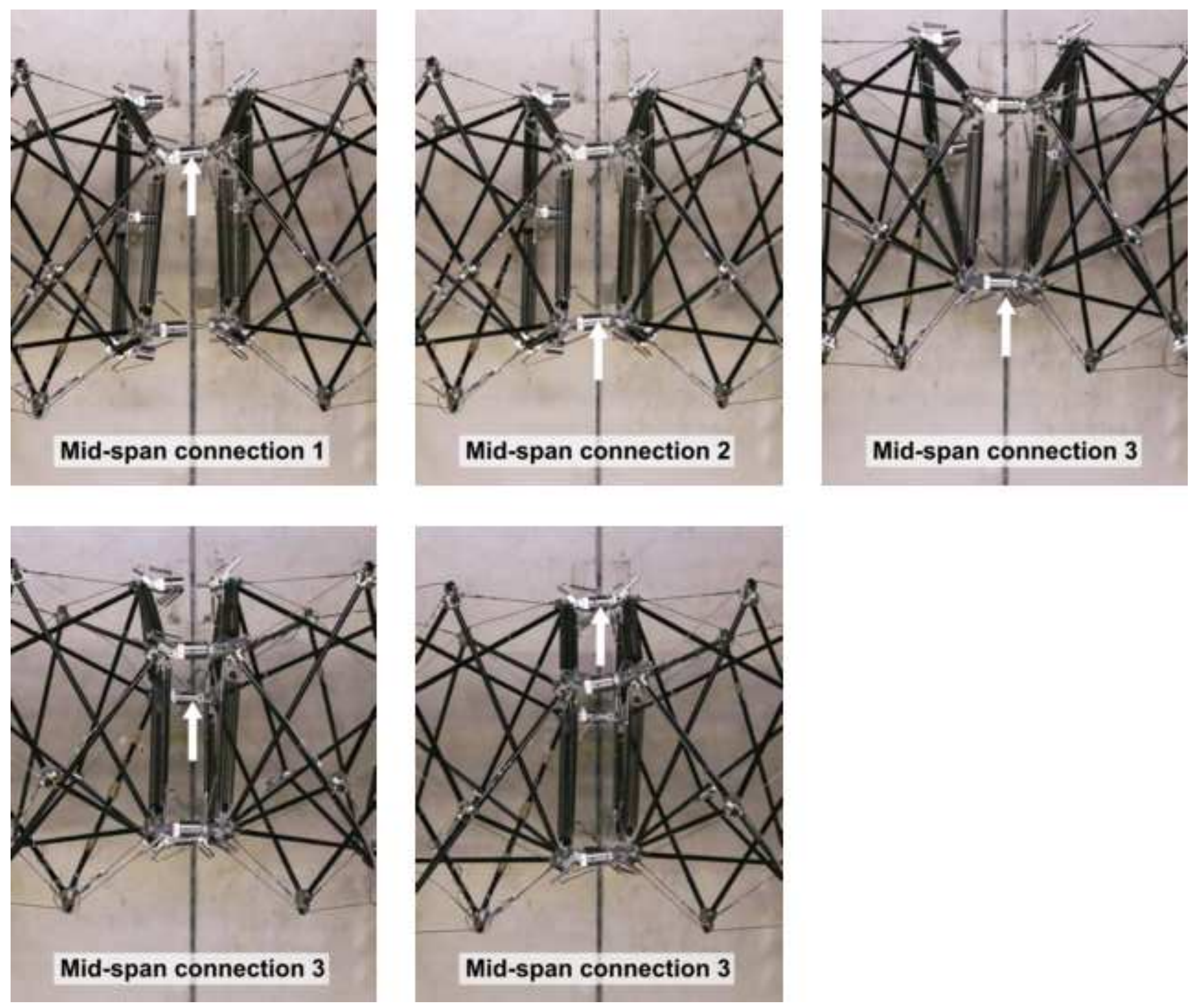